\section{Pollen-Induced Allergic Asthma and Rhinoconjunctivitis: Differences in Outcome Between Seasonal and Nonseasonal Exposure to Allergens Under Real-Life Conditions (The LANDSCAPE Study)}

Dominguez-Ortega $\mathrm{J}^{1}$, Navarro $\mathrm{A}^{2}$, Delgado Romero $\mathrm{J}^{3}$, Dordal $\mathrm{T}^{4}$, Habernau $\mathrm{A}^{5}$, Rodríguez $\mathrm{M}^{6}$, Mur-Gimeno $\mathrm{P}^{7}$, González Gutiérrez $\mathrm{ML}^{8}$, Pérez-Francés $\mathrm{C}^{9}$, Pascual Miravalles $\mathrm{MJ}^{10}$, Colás $\mathrm{C}^{11}$, Dávila $\mathrm{I}^{12}$, Rodríguez Fernández $\mathrm{F}^{13}$, Sánchez Hernández $\mathrm{MC}^{3}$, Valero $\mathrm{A}^{14}$ : The LANDSCAPE STUDY GROUP of the SEAIC

${ }^{1}$ Department of Allergy, Hospital La Paz Institute for Health Research (IdiPAZ), Madrid, Spain

${ }^{2}$ Allergology Clinical Management Unit, Hospital El Tomillar, AGS Sur Seville, Spain

${ }^{3}$ Allergology Clinical Management Unit, Hospital Virgen Macarena, Seville, Spain

${ }^{4}$ Allergy Unit, Department of Internal Medicine, Hospital Universitari de Bellvitge, L'Hospitalet de Llobregat, Spain

${ }^{5}$ Allergy Unit, Department of Internal Medicine, Complejo Hospitalario de Mérida, Badajoz, Spain

${ }^{6}$ Servicio de Enfermedades del Sistema Inmune-Alergia, Hospital Universitario Príncipe de Asturias, Alcalá de Henares, Madrid, Spain

${ }^{7}$ Allergy Unit, Hospital Santa Barbara, Puertollano, Spain ${ }^{8}$ Allergy Service, Hospital Universitario Clinico San Carlos, Madrid, Spain

${ }^{9}$ Department of Allergy, Hospital Universitario Dr, Peset, Valencia, Spain

${ }^{10}$ Allergy Service Clínica Rotger Palma de Mallorca, Spain

${ }^{11}$ Department of Allergy, Hospital Clínico Lozano Blesa, Instituto de Investigación Sanitaria de Aragón, Zaragoza, Spain

${ }^{12}$ Allergy Service, University Hospital of Salamanca, Institute for Biomedical Research of Salamanca (IBSAL), Department of Biomedical and Diagnostic Sciences, Faculty of Medicine, University of Salamanca, Spain

${ }^{13}$ Allergy Service, Hospital Universitario Marqués de Valdecilla, Santander, Spain

${ }^{14}$ Servei de Neumologia i Al-lèrgia, Institut Clinic Respiratori, Hospital Clinic, Barcelona, Spain

J Investig Allergol Clin Immunol 2020; Vol. 30(6): 454-456 doi: $10.18176 /$ jiaci.0544

Key words: Asthma. Pollen. Allergic rhinitis. Seasonal asthma. LANDSCAPE Study.

Palabras clave: Asma. Polen. Rinitis alérgica. Asma alérgica estacional. ESTUDIO LANDSCAPE.

The clinical manifestations of asthma and rhinitis vary with phenotypes and endotypes [1,2]. Sensitization to a specific allergen may involve clinical profiles with significant differences in symptoms, quality of life, and even choice of therapy by specialists $[3,4]$. However, classifications of asthma 
and rhinitis are based mainly on severity and/or control, with no reference to the role of current or absence of exposure to allergens in the development of symptoms. Furthermore, exclusively pollen-allergic patients are not appropriately represented in clinical practice guidelines for asthma and rhinitis.

We performed a multicenter, epidemiological, prospective, observational study to compare clinical and pathophysiological features during and outside the pollen season in adults diagnosed with allergic asthma and rhinitis who manifested exclusively seasonal symptoms caused by grasses and/or olive tree pollens at inclusion.

We defined patients as being allergic to grass and/or olive pollens based on skin prick testing and/or specific IgE (ImmunoCAP, Thermo Fisher Scientific). Patients had to have presented symptoms on exposure to these pollens exclusively during the pollen season and in their geographical area. We excluded pregnant women, patients sensitized to occupational and other perennial or seasonal allergens to which they were exposed during the same period, patients who had previously received immunotherapy, and patients with other associated nasal or bronchial diseases or any other condition recorded during the pollen season. Patients sensitized to allergens other than those studied here were included if their sensitization was not clinically relevant, that is, with no symptoms induced by the allergen in question.

We assessed symptoms and lung function $\left(\mathrm{FEV}_{1}, \mathrm{FVC}\right.$, $\mathrm{FEV}_{1} / \mathrm{FVC}$ ) and recorded the Asthma Control Test (ACT) score, the Mini Asthma Quality of Life Questionnaire (MiniAQLQ) score, fractional inhaled nitric oxide (FeNO), the visual analog scale (VAS) score for rhinitis and conjunctivitis, and the ESPRINT questionnaire score. Sociodemographic data and clinical variables were assessed during and outside the pollen season (autumn and winter), ie, at visit 1 (V1) and visit 2 (V2).

Patients were included at V1 at least 2 weeks after being subject to pollen levels that induced a clinical response ( $>50$ grains $/ \mathrm{mm}^{3}$ for grasses, $>200$ grains $/ \mathrm{mm}^{3}$ for olive) [5] . Each investigator consecutively included patients with a confirmed diagnosis of seasonal allergic asthma and rhinitis caused by grass/olive-tree pollens, with or without allergic conjunctivitis, according to published diagnostic criteria for asthma [6] and rhinitis [7].

Participation in the study by investigators and patients was voluntary, and patients had to sign an informed consent document. The Ethics Committee of Hospital Universitario La Paz approved the study (SEA-ASM-2014-01).

The study population comprised 101 patients (mean [SD] age, 35.79 [10.97] years). Patients were already taking treatment on enrolment, or treatment was prescribed at V1 in $81.3 \%$ of patients with rhinitis and $79.6 \%$ of patients with asthma. At V2, only $2.4 \%$ were receiving treatment for rhinitis and $11.3 \%$ for asthma. Nevertheless, a significant difference was observed between the visits with respect to markers of severity for rhinitis and asthma. At V1, $25 \%$ of patients had intermittent asthma, 28.6\% mild-persistent asthma, $41.8 \%$ moderate-persistent asthma, and $4.1 \%$ severe asthma. At V2, $67 \%$ of patients had no asthma symptoms, $22.4 \%$ had intermittent asthma, 4.1\% had mild-persistent asthma, $6.1 \%$ had moderate-persistent asthma, and $0 \%$ had severe
Table. Clinical Characteristics at Visits 1 and 2

\begin{tabular}{|c|c|c|c|}
\hline & $\begin{array}{l}\text { Visit 1, Mean } \\
\text { (SD [range]) }\end{array}$ & $\begin{array}{l}\text { Visit 2, Mean } \\
\text { (SD [range]) }\end{array}$ & $\begin{array}{c}P \\
\text { Value }\end{array}$ \\
\hline ACT score & $\begin{array}{c}16.59 \\
(5.14[6-25])\end{array}$ & $\begin{array}{c}23.36 \\
(2.54[14-25])\end{array}$ & .0001 \\
\hline AQLQ score & $\begin{array}{c}4.60 \\
(1.29[1.47-7])\end{array}$ & $\begin{array}{c}6.28 \\
(0.81[3.60-7])\end{array}$ & .0001 \\
\hline FeNO, ppb & $\begin{array}{c}57.2 \\
(37.4[10-186])\end{array}$ & $\begin{array}{c}21.9 \\
(10.6[2-61])\end{array}$ & .0001 \\
\hline FVC, L & $\begin{array}{c}3.91 \\
(0.83[1.7-6.1])\end{array}$ & $\begin{array}{c}3.94 \\
(0.85[1.8-6.1])\end{array}$ & .33 \\
\hline $\mathrm{FEV}_{1}, \mathrm{~L}$ & $\begin{array}{c}3.15 \\
(0.70[1.7-5.1])\end{array}$ & $\begin{array}{c}3.25 \\
(0.67[1.4-4.8])\end{array}$ & .01 \\
\hline $\mathrm{FEV}_{1}, \%$ & $\begin{array}{c}94.45 \\
(15.01[52-131])\end{array}$ & $\begin{array}{c}98.06 \\
(14.40[58-127])\end{array}$ & .001 \\
\hline $\mathrm{FEV}_{1} / \mathrm{FVC}$ & $\begin{array}{c}0.80 \\
(0.09[0.5-1])\end{array}$ & $\begin{array}{c}0.84 \\
(0.08[0.7-1])\end{array}$ & .001 \\
\hline ESPRINT 15 score & $\begin{array}{c}2.46 \\
(1.51[0-5])\end{array}$ & $\begin{array}{c}0.28 \\
(0.61[0-3])\end{array}$ & .0001 \\
\hline VAS (rhinitis) & $\begin{array}{c}47.68 \\
(27.54)\end{array}$ & $\begin{array}{c}14.51 \\
(22.48)\end{array}$ & .0001 \\
\hline VAS (conjunctivitis) & $\begin{array}{c}47.3 \\
(29.33)\end{array}$ & $\begin{array}{c}8.4 \\
(17.12)\end{array}$ & .0001 \\
\hline $\begin{array}{l}\text { Symptom score } \\
\text { (conjunctivitis) }\end{array}$ & $\begin{array}{c}7.34 \\
(4.15[0-16])\end{array}$ & $\begin{array}{c}0.81 \\
(1.74[0-10])\end{array}$ & .0001 \\
\hline
\end{tabular}

Abbreviations: ACT, Asthma Control Test; AQLQ, Asthma Quality of Life Questionnaire; FeNO, fractional exhaled nitric oxide; $\mathrm{FEV}_{1}$, forced expiratory volume in 1 second; $\mathrm{FVC}$, forced vital capacity; VAS, visual analog scale.

asthma. At V1, 22.4\% of patients had mild rhinitis, $62.2 \%$ had persistent rhinitis, and $14.3 \%$ had severe rhinitis. At V2, 58.2\% of patients had no rhinitis symptoms, $32.6 \%$ had mild rhinitis, $8.2 \%$ had moderate rhinitis, and only $1 \%$ had severe rhinitis.

Significant differences were observed between the visits with respect to severity for both diseases and for ACT, FeNO, MiniAQLQ, $\mathrm{FEV}_{1}(\%), \mathrm{FEV}_{1} / \mathrm{FVC}$ ratio, VAS for rhinitis and conjunctivitis, and the ESPRINT score, but not for FVC values (Table).

The results of our study confirm exposure to the allergen as the determining factor for the symptoms of allergic asthma and rhinoconjunctivitis. Furthermore, exposure to allergens can affect diagnostic yield in asthma by modifying the results for FeNO and lung function.

However, our findings also show that clinical features do not disappear completely outside the exposure period, as almost one-third of asthmatic patients and $41.8 \%$ of those with rhinitis continued to present symptoms, albeit with clearly lower severity than at V1. Therefore, it seems clear that clinical manifestations in the respiratory tract depend on the allergic response, even during periods when the patient is not directly exposed to the allergen responsible for his/her symptoms. 
Contact with the allergen may cause pathophysiological abnormalities that lead to clinical manifestations [8]. This possibility could prove to be important in circumstances that trigger respiratory symptoms, such as infections or contact with irritants [9].

Furthermore, consistent with the results of similar studies [10], measurement of FeNO as an indicator of the presence of type 2 inflammation [11], also revealed a significant increase during the exposure period, thus indicating that $\mathrm{FeNO}$ could be a sensitive parameter for determining exposure to the allergen. The FeNO value decreased significantly outside the pollen season. In addition, the values of some lung function parameters, such as $\mathrm{FEV}_{1}$, were associated with exposure to the allergen, whereas values such as FVC did not vary significantly, indicating that the presence of clinical manifestations could be more sensitive to limited allergen exposure over time than lung function abnormalities, especially in patients who receive antiasthma treatment.

A potential limitation of the present study is its small sample size. However, the population was very homogeneous, and patient selection was very strict, since patients in whom other possible sensitizations could have had a clinical effect were excluded. While sensitization to multiple allergens is common in Spain [12,13], most patients were sensitized only to pollens whose pollination period was markedly seasonal, such as grasses and olive.

In conclusion, most patients diagnosed with allergic rhinoconjunctivitis and asthma due to sensitization to grass/olive pollens experience clinical manifestations, lung function abnormalities, and airway-inflammation exclusively during the pollen season. However, a few continue to experience abnormalities outside the exposure period.

\section{Acknowledgments}

We are grateful to Mariana Díaz-Almirón, Department of Biostatistics, Hospital Universitario La Paz, Madrid, Spain for her help with the statistical analysis and to Thomas O'Boyle for his help in the preparation of the English version of the manuscript.

\section{Funding}

This study was partially supported by the SEAIC Foundation and GSK

\section{Conflicts of Interest}

The authors declare that they have no conflicts of interest.

\section{References}

1. Moore WC, Meyers DA, Wenzel SE, Teague WG, Li H, Li X, et al. Identification of asthma phenotypes using a clustering analysis in the Severe Asthma Research Program. Am J Respir Crit Care Med. 2010;181:315-23

2. Papadopoulos NG, Bernstein JA, Demoly P, Dykewicz $M$, Fokkens W, Hellings PW, et al. Phenotypes and endotypes of rhinitis and their impact on management: a PRACTALL report. Allergy. 2015;70:474-94.
3. Valero A, Quirce S, Dávila I, Delgado J, Domínguez-Ortega J. Allergic respiratory disease: Different allergens, different symptoms. Allergy. 2017;72:1306-16.

4. Domínguez Ortega J, Quirce S, Delgado J, Dávila I, MartíGuadaño E, Valero A. Diagnostic and therapeutic approaches in respiratory allergy are different depending on the profile of aeroallergen sensitization. Allergol Immunopathol (Madr). 2014:42:11-8

5. Pola Pola J, Subiza Garrido-Lestache JM, Garcia Menaya JM, Porcel Carreño SL. Pólenes de interés en Alergología en nuestro medio. In: Tratado de Alergología. Tomo I. Madrid Ergon,2015. P 247-74.

6. GEMA 2009 (Spanish guideline on the management of asthma). Executive Committee GEMA 2009. J Investig Allergol Clin Immunol. 2010;20 Suppl 1:1-59.

7. Bousquet J, Khaltaev N, Cruz AA, Denburg J, Fokkens WJ, Togias A, et al. Allergic Rhinitis and its Impact on Asthma (ARIA) 2008 update (in collaboration with the World Health Organization, GA(2)LEN and AllerGen). Allergy. 2008;63 Suppl 8:8-160.

8. Schatz M, Rosenwasser L. The allergic asthma phenotype. J Allergy Clin Immunol Pract. 2014;2:645-8.

9. Ramsahai JM, Hansbro PM, Wark P. Mechanisms and management of asthma exacerbations. Am J Respir Crit Care Med. 2019;199:423-32

10. Bake B, Viklund E, Olin AC. Effects of pollen season on central and peripheral nitric oxide production in subjects with pollen asthma. Respir Med. 2014;108:1277-83.

11. Silkoff $P E$, Laviolette $M$, Singh D, FitzGerald JM, Kelsen $\mathrm{S}$, Backer $\mathrm{V}$, et al. Identification of airway mucosal type2 inflammation by using clinical biomarkers in asthmatic patients. J Allergy Clin Immunol. 2017;140:710-9.

12. Migueres $M$, Dávila I, Frati F, Azpeitia A, Jeanpetit $Y$, LhéritierBarrand $M$, et al. Types of sensitization to aeroallergens: definitions, prevalences and impact on the diagnosis and treatment of allergic respiratory disease. Clin Transl Allergy. 2014;4:16

13. Ojeda P, Sastre J, Olaguibel JM, Chivato T; investigators participating in the National Survey of the Spanish Society of Allergology and Clinical Immunology Alergológica 2015. Alergológica 2015: A National Survey on Allergic Diseases in the Adult Spanish Population. J Investig Allergol Clin Immunol. 2018;28:151-64.

Manuscript received April 14, 2020; accepted for publication April 30, 2020.

Javier Domínguez Ortega

Department of Allergy

Hospital Universitario La Paz

Madrid, Spain

E-mail: javier.dominguez@idipaz.es 